\title{
David B. Audretsch, a gatekeeper and qlobetrotter
}

By Silvio Vismara, Katharine Wirsching and Jonah Otto

The final publication is available at https://link.springer.com/chapter/10.1007/978-3-030$\underline{25237-3 \quad 50}$

The authors of this chapter know each other through their connection to their mutual friend, David. They are from Germany, Italy, and the United States. They describe how they got to know David and how he supported them by "opening gates" to research and teaching experiences and much more, always in an international context. Following this, as a paradigmatic example, they focus on a successful international program in which they are all involved, with David.

\section{From acquaintances, to colleagues, to friends (Silvio Vismara)}

June 18, 2012. This is when all started. I had met David a few times before, as I attended some of the workshops and conferences where he delivered keynote speeches. However, I organized my first event directly with David on June 2012. The workshop was entitled "Driving innovation. Challenges for US and Europe: Policy, Research and Practices”, and we enjoyed the participation of some scholars, policy-makers and practitioners. For the first time in my career, I organized something of interest for the local entrepreneurs, managers, and bank officers. Also, for the first time, I organized a workshop that attracted colleagues from different areas and departments. David was there to "open the gates". 
Of course, Erik was there too. Back then, I had known Erik Lehmann for not much more than one year. Still, he gave me total trust and invited some of his dearest colleagues and friends from inside and outside academia. This event was the first of many others. Most importantly, it was the beginning of a relationship that would extend in my ways. Soon after the workshop, David and Zoltan Acs invited me to join the editorial board of Small Business Economics: An Entrepreneurship Journal. I was elated. Six years later, I have managed 169 papers submitted to the journal, plus three special issues (one of them is currently open). Later, I was appointed associate editor of two other journals, the Financial Review and the Journal of Technology Transfer, as well as member of the editorial review board of a few other journals. I don't think this would have been possible without David first opening the gates to editorship.

These are only some of the milestones of this journey. Just to give an example, while I am writing, I am in my hotel room in Chicago, back from a dinner with Chiara (my fiancée), David and Joanne (his wife). Zac Rolnik of Now Publishing was there too. Zac is now a friend, like other executives of publishing companies. As editorial team of Small Business Economics, we meet twice each year, one time at the Academy of Management Conference in the United States and one time in a European branch of Springer Nature. David has invited me a couple of times for workshops and seminars in Bloomington, where he works at the School of Public and Environmental Affairs of the Indiana University. These were other opportunities for me to meet colleagues, and I very much look forward to the seminar I will deliver at IU in April, 2019.

It was in these occasions that I met the rest of David's family. My memories go to his sons; Alex picking me up at the Indianapolis airport with his fancy sporty car, to James playing soccer with me on the Venetian walls of Bergamo, to Christopher playing the piano at the gala dinner of a conference in Bloomington. Unfortunately, differently from four years ago, this summer we did not really get to watch many soccer matches of the World Cup together. Not a 
good year for soccer in Italy and in the States. Despite this, like every year, I met David in the States at the Academy and in Bergamo, for the summer school.

Out of the cooperation with Erik, the University of Bergamo and the University of Augsburg established in 2011 the CISAlpino Institute for Comparative Studies in Europe. This has been an important move to formalize and strengthen the cooperation between the two universities. Over the years, we had over one hundred exchange students. Each year, seven students leave Bergamo to study at Augsburg University as Erasmus students, and vice versa. $\mathrm{PhD}$ students, young scholars, and colleagues frequently spend a research or a teaching period between the two universities. In a recent institutional visit, the two Rectors agreed on a plan to extend this cooperation to other faculties. Last but not least, together with Indiana University, each year we run a summer school.

\section{How I grew up from a chick to a pig on his farm, or: How David supported my academic career (Katharine Wirsching)}

I can still remember where and when I first met David Audretsch. Around 10 years ago in 2008, he received an honorary doctoral degree from the University of Augsburg and thus came to visit Augsburg and Erik Lehmann's chair. At this time, I already worked for Erik's chair for three years as a scientific student assistant and was involved in the organization of the celebration in honor of David. I want to mention that I cannot write about my relation to David without mentioning and thanking my supervisor and mentor Erik. Without his trust in me and promotion of my abilities, he would have never introduced me to his esteemed colleague and old friend, David. My former colleague Alex Starnecker and I first met Dr. Audretsch in our conference room and Erik introduced us as his chicks - we both planned to start working at Erik's chair as $\mathrm{PhD}$ students in 2009. Back then, I was surprised at how open and interested that David was in the two of us. I was expecting a professional expert who had already received 
several honors and was used to being around only those that were his peers. However, David came with his wife and sons; he talked to us young people and was interested in our ideas and plans for the future. From my perspective today, this interest and openness is typical of David and distinguishes him, but at the time, I just did not expect it.

Some time passed after this first meeting and I think the next time I met David was in 2011, when the T2S Annual Meeting took place in Augsburg. Researchers and practitioners presented their papers and ideas about "Technology Transfer in a Global Economy" and for sure, David as a keynote speaker had a decisive influence on the success of this conference. Our social highlight during this conference was an excursion to the Octoberfest in Munich, where we all enjoyed the Bavarian culture with beer, bratwurst and traditional costumes. As always, David and Joanne were pleasant guests and we had a great time together.

During this time, I worked on my doctoral thesis about family firms, their financial performance and innovation behavior. As David is also active in this field of research, our discussions about this topic have helped me a lot. Not only because David has a good overview of related theories and current empirical studies, but also because his cultural experiences and his knowledge about German curiosities from the perspective of an American who has lived in Germany for a long while, our conversations were inspiring for me. As German family firms are often Mittelstand firms (a special kind of medium-sized companies), we also exchanged views on this topic, which is still today one of the main pillars of our joint Summer School program. One could say that our Summer School program itself is a little bit like a German Mittelstand company, run by a more or less old family, involving several generations of researchers with different backgrounds (some are more economists, some more managers or engineers), and all together are responsible for the success of our sustainable product. Like in smaller companies, we have some experts and everybody has their expertise, but in the end all work together, pull in the same direction and have to be able to trust each other and rely on each 
other's work. As will be described later, company visits are essential for the program and the transfer of knowledge and thus, we included various types of companies. One company is my husband's employer, Roschmann IDL, a construction and engineering company for individual steel and glass facades all over the world. Especially in the last years, Roschmann's involvement gives multifaceted insights in the German-American trade relations, as they have many customers in the United States and are directly affected by political changes. This collaboration is helpful for the students and I am grateful for the opportunity to use this personal relation, which makes things easier.

Besides my research on family firms, David also influenced my interest for additional topics. As a passionate and field-influencing researcher on entrepreneurship, he aroused my interest in entrepreneurship. I started researching female immigrant entrepreneurship in Germany and during one of our summer school programs, David suggested to write a joint contribution together with Erik (Female Immigrant Entrepreneurship, in: Link, A. N. (Ed.), Gender and Entrepreneurial Activity. Cheltenham: Edward Elgar Publishing, 2017, 46-68, with D. B. Audretsch and E. E. Lehmann). This was my first publication with David Audretsch as a co-author and writing with him was as pleasant as organizing or discussing. This joint work evolved during my summer in Bloomington in 2016. If I had to decide which support from David was most important to my career, his invitation to visit SPEA and work as a visiting scholar and adjunct lecturer will be near the top. As usual in Germany and thanks to Erik, I already taught a lot at Augsburg. However, the opportunity to teach at the School of Public and Environmental Affairs and be part of the academic community there was a wonderful experience. I really enjoyed teaching an undergraduate course in "Public Policy and Economic Development in Europe", having interesting discussions with the students there and having an immersive experience. 
Being part of David's Institute for Development Strategies and working together with other research fellows is a delightful opportunity to enlarge my research focus and extend my research network. The fact that David likes to expand his network and always gives impulses for new projects and ideas is very helpful for me and promotes my scientific career. A good example are the workshops at the Indiana University Europe Gateway in Berlin. In 2017 and 2018, a group of around 20 interested researchers from Indiana University and all over Europe met and discussed "Entrepreneurship in Times of Increased Competition" as well as "Entrepreneurship and Reigniting Growth in the European Union". These workshops are valuable because the setting allows for having in-depth discussions, and developing and pushing forward new research ideas. One last thing I would like to mention in this section is that David gave me the chance to work for "Small Business Economics: An Entrepreneurship Journal" as member of the editorial review board as well as a guest editor for a special issue about "Entrepreneurship in Context". I hope that there will be a lot more joint projects in the future; and thus, thanks to all the support and encouragement I have received, I will hopefully be in a position to follow David's spirit and then give something back to a younger generation.

\section{First a waive, then the world (Jonah Otto)}

I first met David as a graduate student in my early 20's, having no idea who he was, what his academic background was, what classes he taught or who he was collaborating with; nothing. I had already been studying for my Master of Public Affairs (MPA) degree at the School of Public and Environmental Affairs (SPEA) on the Indiana University campus in Bloomington for an entire semester and our paths had never crossed. In fact, even the day I met him it was simply a five second introduction. He was the academic and strategic director of the SPEA International Office, which was where I was interviewing for a placement as a graduate assistant. I had come to SPEA with dreams of one day becoming an upper-level administrator 
in university international relations, and once I realized that the faculty had its own international office, I knew where I wanted to be. After I was granted the position I was quickly ushered past David's office on my "new guy" tour, even though I wouldn't start work there until the next semester. Little did I know that the man I had briefly waived to would drastically alter the course of my life.

It did not take long for me to realize that working with David would not be like any other position I had held before. After two weeks of completing random odds-and-ends tasks and projects for the full-time staff, David called me into his office out of the blue. Having never said more than, "hi", to me in passing, his first sentence in our first ever meeting was, "Want to be an author?" Naturally, I was caught off-guard, but recovered quickly enough to stammer, "Uh, sure," and just like that, my research career was born. Unbeknownst to me, David had received positive reports about my early work for his team and subsequently recruited me to edit a chapter of a forthcoming project where he and his colleagues were compiling student reports from a summer study abroad program to form a cohesive book of cases in European public policy and economic development. This would go on to become my first publication and sparked an interest within me for this area of academia.

After completing my MPA degree, a year of which I worked in David's office in conjunction with my studies, I was on the hunt for a position within international relations in the university setting. I had cast my net pretty wide geographically, applying to positons on the east and west coasts of the United States, as well as to everywhere in between and multiple countries abroad. However, David played a key role in keeping me close to home. Under his supervision, the full-time staff of the SPEA International Office had greatly expanded the scope of its international relations responsibilities for the faculty, as well as its corresponding programmatic offerings. To effectively accommodate this growth David supported the creation of a new administrative position, the Assistant Director of International Programs, whose 
purview was the creation and management of agreements, partnerships and programming for the faculty with institutions, governments and organizations around the globe. With the recommendation of his staff, David vouched for my application and I was quickly brought in to join the team on a permanent basis where I was able to hit the ground running. This incredible opportunity was absolutely foundational to my early professional development. Not only did David help provide the opportunity for me, but he also provided the space for me to make it my own. I was given the freedom, autonomy and respect that I had always desired in a position; where my contributions to strategy were taken seriously while also being held accountable for my decisions. The ability to learn on the fly, be creative and take ownership over projects prepared me for my future in ways that I am still discovering on a continual basis. I owe a great deal of this to David and his staff at SPEA.

Further, David supported my endeavors to expand my responsibilities at SPEA. Having been spurred by my previous experiences in research and supervising student seminar groups with David, I had decided that I wanted to start teaching undergraduate courses. Again, David backed me for the opportunity and I began teaching courses in international economic development and public policy as well as in cultural competency and immersion, which reignited my passion for working with students. During this time the administrative leader of the office, who was also my direct supervisor, became very ill and had to take a substantial period of time away from work. In her absence, David trusted me to operate as an "interim director" of sorts, granting me the chance to take on responsibilities that I wouldn't have normally been in a position to at such a young age. With his confidence, I was representing our office at budget meetings and advocating for our mission to the faculty's top administrators as well as to the alumni advisory council. The experience of teaching and managing international strategy clarified what I wanted for my career; to not only become a higher education international relations administrator, but to do so while being an academic that contributes to 
teaching and research. By putting his faith in me, David helped me to realize my professional aspirations.

The most recent contribution that David has made to my career was to encourage me to leave. He was approached by his close friend and colleague, Prof. Erik Lehmann, to see if it would be ok to gauge my interest in an opportunity with his team at Universität Augsburg in Germany. Having worked on several projects with him during my time at SPEA, Prof. Lehmann wanted me to undertake a $\mathrm{PhD}$ program under his supervision back at Augsburg. Having benefitted himself from taking a position in Germany early in his career, as well as understanding that obtaining a $\mathrm{PhD}$ was the next step in achieving my professional goals, David encouraged Prof. Lehmann to come to me with the offer. After speaking extensively with David and Prof. Lehmann about pursuing a doctoral degree abroad and about the nuances of moving to a new country, I chose to accept the position; an opportunity which would have never been possible in the first place without David.

In many ways, having the opportunity to get to know David has changed the trajectory not only of my professional career, but also my personal life. Starting by providing me with countless opportunities as a graduate student and young professional, to challenging me to push the boundaries of my comfort zone, David has helped to instill within me a desire to keep learning and growing; to resist settling. Further, his confidence in me has been the source for immeasurable support in my development as an administrator, academic and person as a whole. There is much that I owe to David, but knowing him, I'm sure that he simply wants me to pass it on. 
For a man that did not even obtain his passport until he was already in his thirties, it is remarkable how much work David has undertaken abroad and how important internationalism has become in many aspects of his professional life. This is very apparent in his prolific amount of research and publications, seemingly all of which have taken a global and comparative tone since his initial posting outside the US as a research fellow and professor at the WZB Berlin Social Science Center in the 1980's. What some might not know is how heavily David has incorporated his interest in internationalization into the student-facing portion of his career. Upon returning to the American Midwest and taking up his current distinguished professorship at the School of Public and Environmental Affairs at Indiana University, he was also appointed as the faculty's Director of Overseas Programs; giving him strategic oversight over study abroad programming for students and members of the faculty. In this capacity, David collaborated with his close colleague Erik from his time overseas to create what has become a central piece of the international offerings of three institutions: the Summer School.

What started as a dinner and a conversation between friends and colleagues has gone on to become so much more. From its exciting, yet cautious roots, the Summer School program has grown into an expansive endeavor that has brought together two continents, three universities, well over two hundred students and numerous cultures (see figure 1). 


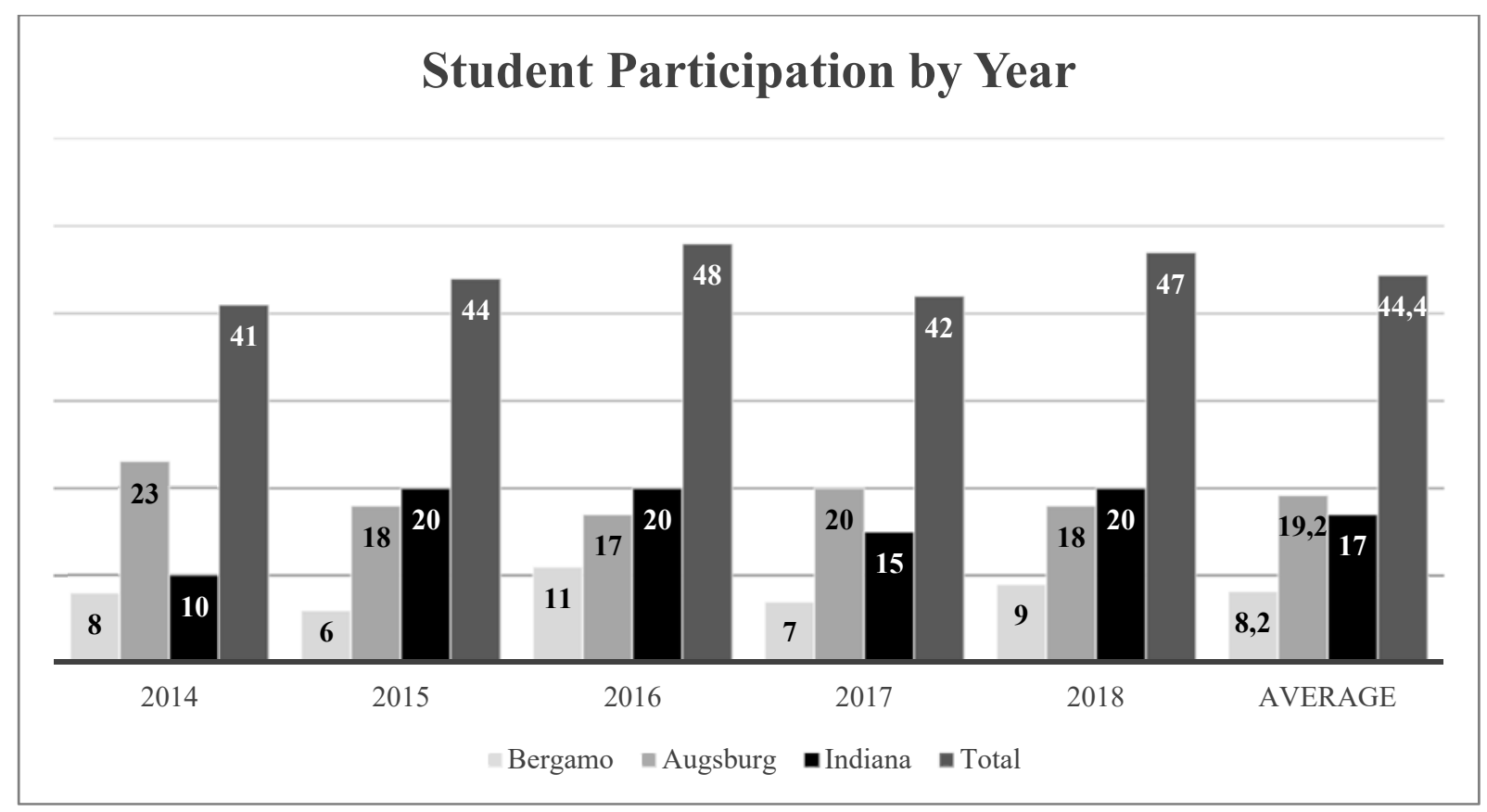

Figure 1: Student participation to the Summer School program by university and year

With his fellow co-directors, Prof. Silvio Vismara and Prof. Erik Lehmann, the leadership of the program nurtured a formal partnership between Universität Augsburg, Università degli studi di Bergamo and Indiana University that has resulted in an intensive, three-week seminar course that brings together graduate and undergraduate students from all three institutions to work together on group projects that address regional economic development and public policy. The program is designed so that the students not only benefit from hands-on academic training, but they also are able to build invaluable skills in international project management and crosscultural competence by working in intercultural teams on rigorous research projects. This is ensured by requiring that every group have no more than $50 \%$ of its members from just one university.

The Summer School is co-hosted by the Università degli studi di Bergamo and Universität Augsburg, splitting the program duration between the two locations. The content of the seminar is comprised of lectures, guest speakers, site visits and cultural excursions so as to maximize the breadth and depth of experience for the students that attend. Through lectures and 
talks from various voices and areas of expertise, the students are exposed to the expansive and interdisciplinary nature of economic development and are provided with a theoretical foundation and examples of practical application. By making site visits to smaller, family-run firms as well as large, multinational corporations in the local community, the students learn about the important role of private enterprise in economic development, as well as the benefits of nurturing a diversified regional economy. The cultural excursions teach the valuable, yet often ignored, lesson of context; that the historical and cultural context of a place bears significant implications for regional economies and the public policies that are intended to shape them. At the conclusion of the program, the students formally present their findings to demonstrate what they have learned and show the progress that they have made towards their group papers. They then use the feedback from the presentations to finalize their work.

Aside from the efforts of David and his colleagues, the students of the Summer School have truly been its driving force: providing the demand for such a program, contributing greatly to in-class discussion and giving valuable feedback so that the program can be refined and improved each year. While the Summer School been able to serve a large number of students in total (222), the program has also been popular from the very beginning and has maintained a consistently high level of student interest each year, never having less than 41 students in a given year. While the number of students from each university is significant, what is not shown is that there are far more nationalities and cultures represented in the data than just Italian, American and German. Owing to the internationalized student bodies at each of these universities, every iteration of the Summer School has had a very diverse population. Not only are the students culturally diverse, but they are academically diverse as well. The Indiana University students come from a public affairs background, the Università degli studi di Bergamo students study engineering management, and the Universität Augsburg students are trained in various disciplines within business and economics. 
The academic focus of the Summer School revolves around the group projects: consulting-style reports where the students outline an economic development problem within a place (municipality, city, region, etc.) and propose public policy recommendations within the context of strategic management. At the beginning of the course, students arrange themselves into groups of four or five, with the caveat that no more than two group members can come from the same university. This not only ensures that each group has multiple cultural perspectives, but that each group will also have different academic nuances. With the groups being comprised as such, they are instructed to take a multicultural and interdisciplinary approach to their work. Each group selects a place and an issue that is hindering economic development within that place, then they are tasked with combining their own independent research with the lessons learned from the readings, lectures, site visits and cultural excursions to formulate strategic recommendations that policy-makers within that place can use to appropriately manage and improve local economic development. In the first year of the Summer School, the resulting papers were published within a book edited by David and his colleagues: Globalization and Public Policy: A European Perspective (2015).

While typical lectures and assigned readings are essential to providing the students with a theoretical foundation in economic development and the strategic management of places, these methods alone do not sufficiently equip the students to understand best practices, and worst mistakes, that policy makers and economic actors make in regional ecosystems. The best way to be exposed to this type of practical application is to meet local decision makers and see the outcomes of their strategies and policies first-hand. Leveraging the geographic locations of the Summer School and the relationships that have been forged and nurtured by David and his fellow co-directing professors, the students are not only given the opportunity to hear from economic development experts, government officials, corporate executives, socially-minded entrepreneurs and non-governmental organization leaders, but they are often able to visit their 
work places too. Throughout the years the Summer School has been fortunate to welcome high profile guest speakers (such as the U.S. Consul General of Munich and a former Senior Vice President of American Express Bank) and gain rare access to public sites and private firms (such as KUKA Robotics Corporation, MAN Group, the Bavarian Center for Transatlantic Relations, Roschmann IDL and Weisser Spulenkörper). This wide array of guest speakers and site visits has given the Summer School students an invaluable look at economic development and the strategic management of places in action; living case studies displaying how publicprivate partnerships and governmental policy and support can lead to economic prosperity. In this manner, the hands-on nature of the Summer School is a crucial component of the student learning process and greatly informs the final products of the student groups.

The final, yet vitally important, components of the Summer School are the cultural excursions. One of the key lessons to be learned in the strategic management of the economic performance of a place is that culture and context matter. It is often the case that a policy solution that works in one place cannot simply be implemented elsewhere without at least some modification, and this is owed to the unique cultural and historical considerations of each place. Cultural excursions are built into the program of the Summer School for this reason; so that students can understand the specific nuances of where they are studying and be able to compare and contrast with the context of their home. This enables the students to dig into the background of a place, identifying root causes of economic and social issues so that they may tailor their policy recommendations in a way that addresses these causes, and doesn't merely put a bandage on the symptoms. The cultural excursions also provide an insight into the preservation, operation, marketing and management of historical and cultural sites, showing how these resources can be included in a local portfolio for economic development.

David and Internationalization: Not just programs, but people. 
As one can see, David has invested a tremendous amount of time and effort into programs such as the Summer School, reflecting the value he sees in internationalization. For David, the Summer School serves as a shining example of his dedication to his students; ensuring that they have affordable access to global experiences that will pay immeasurable dividends to them and those that they come into contact with in the future. However, the students are not the only ones that have been on the receiving end of David's generosity, as is evidenced by the incredible impact that he has had on the lives and careers of the three authors of this chapter. No matter who you are or where you come from, David sees potential and is always willing to lend a hand in your development. He has a way of finding the best in people and maximizing it; not for his own gain, but because he genuinely cares. Having the opportunity to learn and grow in an international context has greatly benefitted David throughout his life and career, and because of the giving person that he is, the opportunities and benefits have not stopped with him but continue to spread. 